\title{
Costunolide Induces Apoptosis via Modulation of Cyclin-Dependent Kinase in HL-60 Human Leukemia Cells
}

\author{
Dong Hee KIM ${ }^{1}$, Jung-Hye $\mathrm{CHOI}^{2}$, Hee-Juhn PARK ${ }^{3}$, Jae-Hoon PARK ${ }^{4}$, and Kyung-Tae LeE ${ }^{5, *}$ \\ ${ }^{1}$ Department of Ophthalmology, Chungju Hospital, KonKuk University School of Medicine, Chungju 380-704, \\ ${ }^{2}$ Department of Oriental Pharmaceutical Science, College of Pharmacy, Kyung Hee University, Seoul 130-701, \\ ${ }^{3}$ Department of Pharmaceutical Engineering, Sangji University, Wonju 220-702, ${ }^{4}$ Department of Pathology, College of Medicine, \\ Kyung Hee University, ${ }^{5}$ Department of Biochemistry, College of Pharmacy, Kyung Hee University, Seoul 130-701, Republic of Korea
}

(Received April 13, 2010; Revised April 22, 2010; Accepted April 22, 2010)

\begin{abstract}
Costunolide is an active compound isolated from the stem bark of Magnolia sieboldii, and is considered a potential therapeutic for the treatment of various cancers. In this study, we investigated the underlying mechanism whereby costunolide induces the apoptosis of human leukemia cells. Using apoptosis analysis and quantitative reverse transcription-polymerase chain reaction (RT-PCR) results obtained during this study show that costunolide is a potent inducer of apoptosis and that it is triggered due to the premature activation of Cdc2. $\mathrm{G}_{1}$-synchronized cells, which cannot undergo mitosis, were found to be more sensitive to costunolide, and Cdc2 mRNA levels were increased by costunolide treatment. Furthermore, the Cdk inhibitors, olomucine and butyrolactone I, were found to suppress costunolide-induced apoptosis. In addition, the PKC activator TPA rescued cells from cell death by costunolide, and this was prevented by the PKC inhibitor staurosporin. The present study suggests that costunolide induces the apoptosis of HL-60 leukemic cells by modulating cyclin-dependent kinase $\mathrm{Cdc} 2$.
\end{abstract}

Keywords: Costunolide, Apoptosis, Cdc2, Leukemia cell

\section{INTRODUCTION}

Costunolide is a sesquiterpene and is found in the stem bark of Magnolia sieboldii, and it is known to have various biologic effects, which including anti-ulcer effects and the inhibition of hepatitis B virus surface antigen (Mori et al., 1994; Chen et al., 1995). Furthermore, costunolide markedly inhibits the killing function of cytotoxic $T$ lymphocytes by preventing granule exocytosis, the production of inositol phosphatase, and tyrosine phosphorylation in response to the crosslinking of T cell receptors (Taniguchi et al., 1995). Recently, costunolide was found to have preventive effects on intestinal carcinogenesis (Mori et al., 1994). We previously demonstrated that costunolide induces the apoptosis of human leukemia cells by inducing ROS-mediated mitochondria permeability transition and consequent cytochrome c release (Lee et al., 2001; Choi et al., 2002).

Apoptosis is a physiological process of cell death that

${ }^{*}$ Corresponding author

Tel: +82-2-961-0860 Fax: +82-2-962-0860

E-mail: ktlee@khu.ac.kr eliminates unwanted, harmful, or neoplastic cells. Thus, cell populations are controlled, autoreactive immune cells are eliminated, and virus-infected and neoplastic cells are killed by apoptosis (Jacobson et al., 1997). Furthermore, various exogenous and endogenous stimuli, such as, receptor-ligand interactions (Tode et al., 1999), radiation (Hendry et al., 1995), cytokine (Larrick and Wright, 1990), and anti-cancer drugs (Hickman, 1992) induce apoptosis, which characteristically results in chromatin condensation, the formation of apoptotic bodies, and DNA fragmentation. Furthermore, it has been shown that some cancer chemotherapeutics and chemopreventives exert their effects by triggering either apoptotic cell death or cell cycle transition, and thus, the induction of tumor cell apoptosis is used to predict tumor treatment response (Kim et al., 1999). On the other hand, several tumor promoters have been shown to inhibit apoptosis (Wright et al., 1994).

There are several routes leading to apoptosis according to specific stimuli. It has been proposed that apoptosis is the result of aberrant cell cycle control, whereby the inappropriate activation of cell cycle-regulatory elements in postmitotic cells results in entry into an abortive cell cycle 
(14). Furthermore, some lines of evidence suggest that aberrant cell cycle control is closely related to the induction of apoptosis. 1) The morphologic features of apoptosis resemble the mitotic catastrophe observed in cells overexpressing Cdc2 at an inappropriate time during the cell cycle (Castedo et al., 2002a; Villaret et al., 2002). 2) Several genes associated with the cell cycle are aberrantly activated during apoptosis (Qin et al., 1994; Castedo et al., 2002a). 3) Cells in the $S$ phase of the cell cycle are more susceptible to apoptosis by various stimuli than when in Go/G 1 phase (Terui et al., 1995). Cdc2 (also called p34Cdc2 and cyclin-dependent kinase 1 (Cdk1)) interacts with cyclin B1 to regulate transition from $G_{2}$ into the $M$ phase (Norbury and Nurse, 1992), and Cdc2 activation appears to be a prerequisite for apoptosis under particular conditions, for example, the paclitaxel-induced apoptosis of breast cancer cells (Yu et al., 1998), during which ErbB2 inhibits apoptosis by inactivating Cdc2, and the HIV-1-induced apoptosis of HeLa Env and HeLa CD4 cells (Castedo et al., 2002b).

In this study, we investigated the effects of costunolide on the activation of Cdc2 and on the apoptosis of human leukemia cells.

\section{MATERIALS AND METHODS}

\section{Chemicals}

Costunolide used for this study was isolated from the stem bark of Magnolia sieboldii as previously described (Choi et al., 2002). The identity of isolated compound was confirmed by HPLC and was found to be $>98 \%$ pure. Aphidicolin, Nocodazol, olomucine, and phorbol 12-O-tetradecanoylphorbol 13-acetate (TPA) were purchased from Calbiochem (La Jolla, CA). All other chemicals were ordered from Sigma (St. Louis, MO) unless otherwise specified.

\section{Cell culture and measurement of apoptosis}

The HL-60 human leukemic cell line was obtained from the American Type Culture Collection (Rockville, MD) and cultured in RPMI 1640 medium (Gibco BRL, Grand island, NY) with $10 \%$ heat inactivated fetal bovine serum in a $37^{\circ} \mathrm{C}, \mathrm{CO}_{2}$ incubator in the presence or absence of chemicals. Costunolide, dissolved in dimethyl sulfoxide (DMSO), was added (the final DMSO concentration in all assays did not exceed $0.1 \%$ ). After each incubation time, the cells were harvested and stained with 4,6-diamidino-2-phenylindole (DAPI). Apoptotic nuclei were counted under an immunofluorescent microscope.

\section{Cell cycle analysis}

For assays of cell cycle and fragmentation of chromosomal DNA, $1 \times 10^{6}$ cells were collected by centrifugation and washed two times with PBS. The cells were fixed in $2 \%$ paraformaldehyde and stained overnight with propidium iodide $(100 \mu \mathrm{g} / \mathrm{ml})$ in PBS containing RNase A $(500 \mu \mathrm{g} / \mathrm{ml})$ at $4^{\circ} \mathrm{C}$. The cell cycle profile and hypodiploid DNA were determined by flow cytometry (FACScaliver, Becton Dickinson, CA) using the CellQuest program.

\section{Reverse transcription PCR}

Total cellular RNA was extracted from costunolidetreated and untreated cells by the single-step method (Chomczynski and Sacchi, 1987). Deoxyribonuclease I-treated RNA $(1 \mu \mathrm{g})$ was converted to complementary DNA by reverse transcription using random hexamer primer and MoMuLV reverse transcriptase (Gibco-BRL, NY) For semi-quantitative evaluations by polymerase chain reaction, we initially performed the PCR reaction over a range of cycles $(22,24,26,28,30,32$ and 34 cycles). The PCR products between 28-32 cycles were observed to be within the logarithmic phase of amplification with the primers of GAPDH and Cdc2. Primers for Cdc2 were; sense 5'-ATGGATCTGAAGAAATACTT-3', antisense 5'-GGAAACTTTTT GTCAGAAAG-3'. PCR was performed for 30 cycles at $95^{\circ} \mathrm{C}$ for 45 seconds, $58^{\circ} \mathrm{C}$ for 45 seconds, and $72^{\circ} \mathrm{C}$ for $1 \mathrm{~min}$ (Perkin-Elmer, Norwalk, CT). Ten $\mu \mathrm{g}$ of RT-PCR products were resolved on $2 \%$ agarose gels and subjected to Southern blot analysis to confirm the specificity of amplification using a biotinylated internally positioned oligonucleotide (sense; 5'-ATGAGGTAG TAACACTCTGG-3') as a probe for chemiluminescence detection. Quantitation of expression level was achieved by densitometry (Bio-Rad, Hercules, CA).

\section{RESULTS AND DISCUSSION}

\section{Cell cycle arrested-cells were more susceptible to costunolide-induced apoptosis}

We previously demonstrated that costunolide induces the apoptosis of human leukemia cells. In the present study, costunolide was found to induce apoptosis in a dose-dependent manner up to $10 \mu \mathrm{M}$ (Fig. 1A). However, apoptotic rates did not exceed $60 \%$ even when cells were treated with high concentrations of costunolide $(20 \mu \mathrm{M})$, and apoptosis-resistant cells showed no morphologic evidences of cell damage (Fig. 1B), which suggests that susceptibility to costunolide is may be dependent on cell cycle.

To determine the effects of costunolide at various points in the cell cycle, cells were synchronized by serum starva- 
Dong Hee Kim et al.

(A)

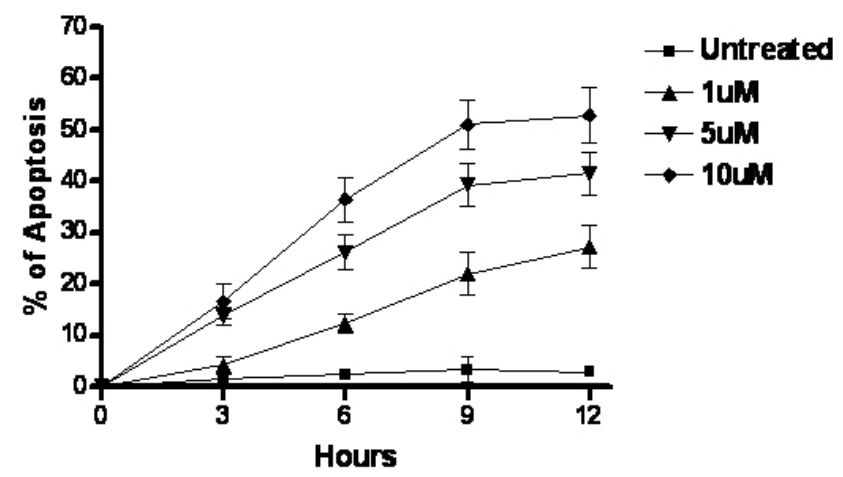

(C)

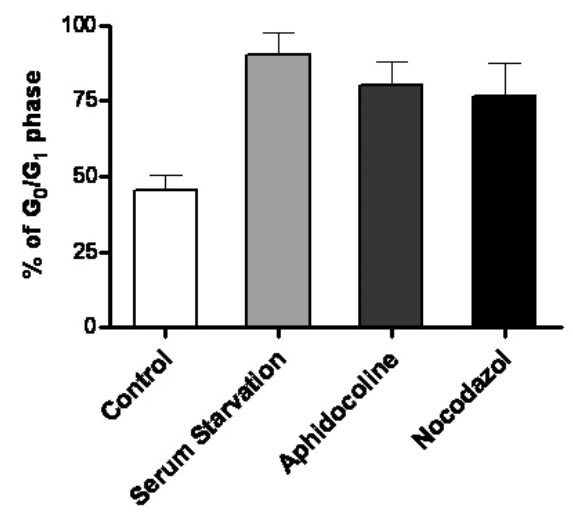

(B)

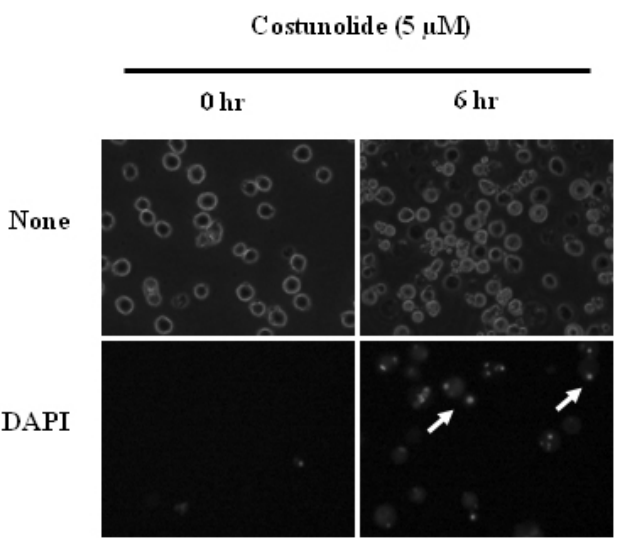

(D)

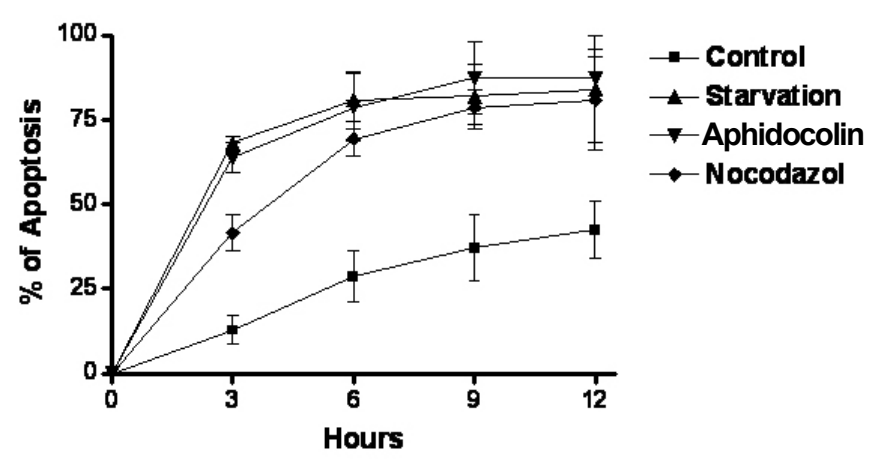

Fig. 1. Apoptosis of HL-60 cells by costunolide in cell cycle arrested cells. (A) Cells were incubated with 1,5 , or $10 \mu \mathrm{M}$ costunolide. After the indicated times, cells were harvested, stained with DAPI and numbers of apoptotic nuclei were counted under a fluorescent microscope. Percentages of apoptotic cells are shown. (B) Morphological changes after treatment with $5 \mu \mathrm{M}$ costunolide were observed under a fluorescent microscope. (C) Cells were synchronized in the $G_{1}$ phase of the cell cycle by serum starvation for 3 days, treating them with $2 \mu \mathrm{g} / \mathrm{ml}$ aphidocolin for 1 day or with $0.4 \mu \mathrm{g} / \mathrm{ml}$ nocodazol for 1 day. The cell cycle profiles were determined using $\mathrm{G}_{0} / \mathrm{G}_{1}$ percentages. (D) After cell cycle arrest, cells were treated with $5 \mu \mathrm{M}$ costunolide for the indicated times and apoptotic cells were counted by DAPI staining. Control cells were cultured in regular media containing 10\% FBS and treated with $5 \mu \mathrm{M}$ costunolide. Data represent the means \pm SEM of three independent experiments.

tion for 3 days. Ninety percent of these serum starved cells arrested at $\mathrm{G}_{1}$ (Fig. 1C), and these synchronized cells were then stimulated by costunolide at $5 \mu \mathrm{M}$ (Fig. 1D). Sixty-eight percent of the serum deprived $\mathrm{G}_{1}$-arrested cells underwent apoptosis within $3 \mathrm{hr}$, as compared to only $14 \%$ of apoptosis in cells growing in regular medium (Fig. 1C). To verify the relationship between cell cycle and induction of apoptosis by costunolide, we explored apoptosis rates after cell cycle restriction by aphidicolin, an inhibitor of DNA polymerases $\alpha$ and $\delta$, and nocodazol, an inhibitor of microtube formation. Eighty percent of cells were arrested in the $\mathrm{G}_{1}$ phase after $24 \mathrm{hrs}$ of treatment with aphidicolin (2 $\mu \mathrm{g} / \mathrm{ml})$ or nocodazol $(0.4 \mu \mathrm{g} / \mathrm{ml})$ (Fig. 1C). When the cell cycle-arrested cells were incubated with $5 \mu \mathrm{M}$ costunolide, the aphidicolin- and nocodazol-preincubated cells underwent apoptosis about $2 \%$ and $3 \%$ by $0 \mathrm{hr}, 63 \%$ and $40 \%$ by
$3 \mathrm{hr}, 78 \%$ and $66 \%$ by $6 \mathrm{hr}$, and $86 \%$ and $78 \%$ by $9 \mathrm{hr}$, respectively (Fig. 1D). These results show costunolide induces apoptosis more effectively in cell cycle-arrested cells.

\section{Cdc2 was transcriptionally activated by costunolide}

To investigate the effects of the cell cycle on costunolide-induced apoptosis, we investigated the expression of Cdc2 mRNA in costunolide-treated cells by semi-quantitative RT-PCR. Cells were synchronized by serum starvation for 3 days and then, incubated with $5 \mu \mathrm{M}$ costunolide. They were then harvested after in $10,20,30,40,50$, and $60 \mathrm{~min}$ of costunolide treatment and analyzed by semi-quantitative RT-PCR, as described in Methods. Cdc2 mRNA expression was found to be transcriptionally activated from $20 \mathrm{~min}$ after costunolide treatment with a peak at $40 \mathrm{~min}$ 
(Fig. 2), which suggests that costunolide activated Cdc2 gene expression. However, we failed to observe any significant change in the levels of cyclin B1, which interacts with $\mathrm{Cdc} 2$ to regulate transition from $\mathrm{G}_{2}$ into the $M$ phase (data not shown).

\section{Cdk inhibitors rescue cells from costunolide-induced apoptosis}

In order to elucidate the relationship between Cdc2 expression and costunolide-induced apoptosis, we investigated the effects of the Cdk inhibitors, olomucine, and butyrolactone I, on costunolide-induced apoptosis. HL-60 cells were pretreated with olomucine $(20 \mu \mathrm{M})$ and butyrolactone I $(10 \mu \mathrm{M})$ for $24 \mathrm{hr}$, and then incubated in media containing $5 \mu \mathrm{M}$ costunolide for $3,6,9$, and $12 \mathrm{hr}$.

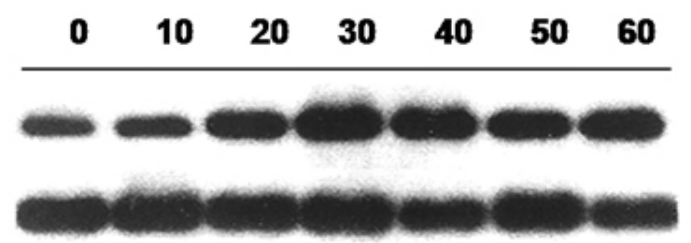

Cdc2

GAPDH

Fig. 2. Expression of Cdc2 mRNA during costunolide-induced apoptosis. Cells were treated with $5 \mu \mathrm{M}$ costunolide for the indicated times. RNA was then extracted and semi-quantitative RT-PCR was performed as described in Materials and Methods. The data shown represent three independent experiments.

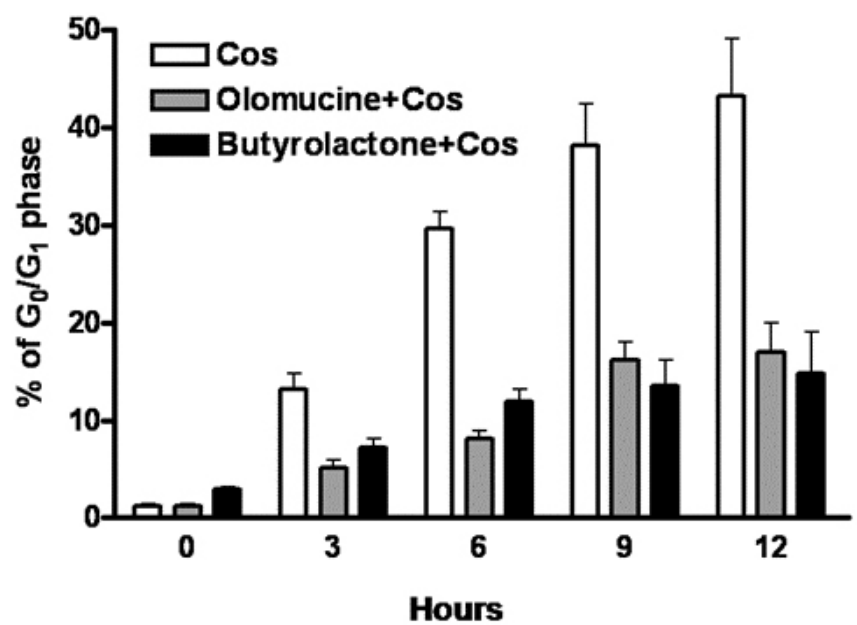

Fig. 3. Costunolide-induced apoptosis was inhibited by the Cdk inhibitors olomucine or butyrolactone I. Cells were pre-treated with $20 \mu \mathrm{M}$ olomucine or $10 \mu \mathrm{M}$ butyrolactone I for 24 hours, and then cultured in the presence of $5 \mu \mathrm{M}$ costunolide for the indicated times. Apoptotic cells were counted and their percentages are presented. Data represent the means \pm SEM of three independent experiments.
Olomucine- and butyrolactone-pretreated cells underwent apoptosis by $5 \%$ and $7 \%$ after $3 \mathrm{hr}, 9 \%$ and $12 \%$ after $6 \mathrm{hr}$, and $17 \%$ and $14 \%$ by $9 \mathrm{hr}$ of costunolide treatment, as compared with $12 \%, 30 \%$, and $38 \%$ in Cdk inhibitor-untreated and costunolide-treated control cells, respectively (Fig. 3). These results show that Cdk, especially premature Cdc2, activation is involved in costunolide-induced apoptosis.

\section{The PKC activator, TPA, prevented cells from costunolide-induced apoptosis}

Protein kinase $\mathrm{C}(\mathrm{PKC})$ is known to regulate the cell growth/cell cycle progression and differentiation (Black, 2000). In order to test the involvement of PKC activity in costunolide-induced apoptosis via Cdc2 activation, we investigated the effects of the PKC activator TPA, on costunolide-induced apoptosis. Cells were initially exposed to TPA $(20 \mu \mathrm{M})$ for $12 \mathrm{hr}$ and then incubated with $5 \mu \mathrm{M}$ costunolide. Less than $10 \%$ of TPA-treated cells underwent apoptosis after $9 \mathrm{hr}$ of costunolide treatment, as compared with $38 \%$ of unstimulated cells (Fig. 4). To confirm that apoptosis resistance was due to PKC activation, we treated cells with TPA or staurosporin $(0.5 \mu \mathrm{M}$, a PKC inhibitor). Cells that were pretreated in TPA or staurosporin were found to be more sensitive to apoptosis by costunolide than cells cultured with TPA only, indicating that PKC activation inhibits costunolide-induced apoptosis (Fig. 4).

Several models have been described that induce apoptosis using a number of different stimuli, such as, depriva-

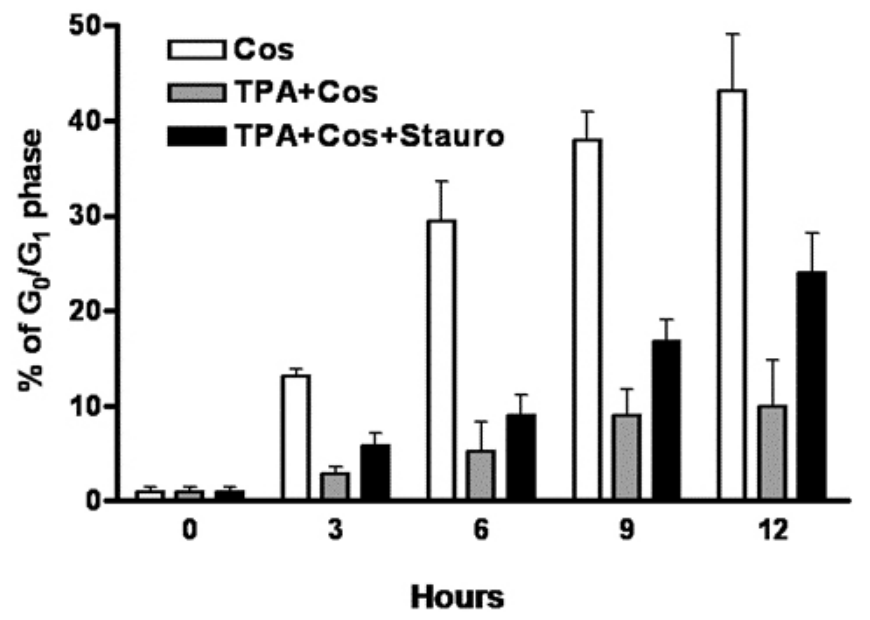

Fig. 4. TPA inhibited costunolide-induced apoptosis. Cells were cultured in the presence of TPA $(20 \mu \mathrm{M})$ for 1 day and then treated with $5 \mu \mathrm{M}$ costunolide or costunolide plus staurosporin $(0.5 \mu \mathrm{M})$ for indicated times. The control cells were cultured without TPA but treated with costunolide. Data represent the means \pm SEM of three independent experiments. 
tion of growth factors (Wang et al., 2006), surface receptor-ligand binding (Tode et al., 1999), cytokines (Larrick and Wright, 1990), DNA damage (Kaufmann, 1989), and abortive cell cycle progression (Furukawa et al., 1996). The ability of a cell to undergo apoptosis in response to a death signal is related to its proliferative status, cell cycle position, and to the controlled expression of genes that affect the cell-death program. Many stimuli can alternatively drive proliferation or induce cell death, which demonstrates the close link between cell cycle progression and cell death (Alderson et al., 1993). Moreover, many of the morphological manifestations of cell death resemble mitotic processes, which involve dismantling the nuclear membrane and lamina, the condensation and segregation of chromosomes, and reorganization of the cytoskeleton (Dunphy and Newport, 1988). Furthermore, M-phase kinase activity, which is critical to cell death process, resides in 34-kDa polypeptide known as Cdc2.

Our data support that costunolide induces apoptosis via the premature unscheduled activation of $\mathrm{Cdc} 2$ and the resulting abortive cell cycle progression. We present the following evidence: [1] $\mathrm{G}_{1}$-synchronized cells, which are not ready for mitosis, were found to be more susceptible to costunolide-induced apoptosis. We synchronized the cells in the $\mathrm{G}_{1}$ phase by serum starvation for 3 days or aphidicolin $(2 \mu \mathrm{g} / \mathrm{ml})$ or nocodazol $(0.4 \mu \mathrm{g} / \mathrm{ml})$ for 1 day. in this condition, mild levels of apoptosis were observed in HL-60 cells. To rule out the possibility that the increased sensitivity of apoptosis was due to the mild apoptosis by serum starvation, aphidicolin, or nocodazol, we tested apoptosis susceptibility to another pro-apoptotic anti-cancer agent, etoposide. No significant difference was found between apoptosis sensitivity to etoposide between $\mathrm{G}_{1}$-synchronized cells and unsynchronized control cells, which confirmed the cell cycle specificity of costunolide-induced apoptosis (data not shown). [2] Cdc2 mRNA expression levels were elevated in cells stimulated with costunolide for $\mathbf{2 0 ~} \mathrm{min}$, as shown by Fig. 2. The requirements of Cdc2 activation for apoptosis are supported by previous observations that CD3 ligation (Fotedar et al., 1995), DNA damage (Tsuruta et al., 2004), TNF- $\alpha$ (Meikrantz et al., 1994), and Fas/ Apo-1 (Kishore et al., 2003) induce Cdc2 activation. [3] Furthermore, the Cdk and Cdc2 inhibitors, olomucine, and butyrolactone I, rescued cells from costunolide-induced apoptosis (Fig. 3). These data strongly suggest that costunolide induces apoptosis via abortive cell cycle control, involving premature $\mathrm{Cdc} 2$ activation.

Protein kinase $C$ acts as a cell growth stimulator via the Raf-1 pathway or is involved in anti-apoptotic signaling via the Bcl-2 pathway (May et al., 1994). In our experiments, the PKC activator TPA rescued cells from apoptosis and this rescue was slightly prevented by the PKC inhibitor staurosporin (Fig. 4). In a previous report, we demonstrated that $\mathrm{Bcl}-2$ overexpression significantly blocks costunolide-induced apoptosis in human leukemia U937 cells (Choi et al., 2002). These observations raise the possibility that costunolide-induced apoptosis is mediated by the PKC-mediated $\mathrm{Bcl}-2$ pathway. In addition, it remains to be elucidated whether Cdc2 activation is associated with the PKC pathway during costunolide-induced apoptosis.

In conclusion, the present study demonstrates that the sesquiterpene costunolide is a potent inducer of apoptosis in human leukemia cells and that it acts as a PKC inhibitor by prematurely activating $\mathrm{Cdc} 2$.

\section{ACKNOWLEDGMENTS}

This work was supported by a grant No. R13-2002020-01002-0 from the Korea Science \& Engineering Foundation and by Seoul Research and Business Development Program (10524).

\section{REFERENCES}

Alderson, M. R., Armitage, R. J., Maraskovsky, E., Tough, T. W., Roux, E., Schooley, K., Ramsdell, F. and Lynch, D. H. (1993). Fas transduces activation signals in normal human T lymphocytes. J. Exp. Med. 178, 2231-2235.

Black, J. D. (2000). Protein kinase C-mediated regulation of the cell cycle. Front. Biosci. 5, D406-423.

Castedo, M., Perfettini, J. L., Roumier, T. and Kroemer, G. (2002a). Cyclin-dependent kinase-1: linking apoptosis to cell cycle and mitotic catastrophe. Cell Death Differ. 9, 1287-1293.

Castedo, M., Roumier, T., Blanco, J., Ferri, K. F., Barretina, J., Tintignac, L. A., Andreau, K., Perfettini, J. L., Amendola, A., Nardacci, R., Leduc, P., Ingber, D. E., Druillennec, S., Roques, B., Leibovitch, S. A., Vilella-Bach, M., Chen, J., Este, J. A., Modjtahedi, N., Piacentini, M. and Kroemer, G. (2002b). Sequential involvement of Cdk1, mTOR and p53 in apoptosis induced by the HIV-1 envelope. EMBO J. 21, 4070-4080.

Chen, H. C., Chou, C. K., Lee, S. D., Wang, J. C. and Yeh, S. F. (1995). Active compounds from Saussurea lappa Clarks that suppress hepatitis $B$ virus surface antigen gene expression in human hepatoma cells. Antiviral Res. 27, 99-109.

Choi, J. H., Ha, J., Park, J. H., Lee, J. Y., Lee, Y. S., Park, H. J., Choi, J. W., Masuda, Y., Nakaya, K. and Lee, K. T. (2002). Costunolide triggers apoptosis in human leukemia U937 cells by depleting intracellular thiols. Jpn. J. Cancer Res. 93, 1327-1333.

Chomczynski, P. and Sacchi, N. (1987). Single-step method of RNA isolation by acid guanidinium thiocyanate-phenolchloroform extraction. Anal. Biochem. 162, 156-159.

Dunphy, W. G. and Newport, J. W. (1988). Mitosis-inducing 
factors are present in a latent form during interphase in the Xenopus embryo. J. Cell Biol. 106, 2047-2056.

Fotedar, R., Flatt, J., Gupta, S., Margolis, R. L., Fitzgerald, P., Messier, H. and Fotedar, A. (1995). Activation-induced T-cell death is cell cycle dependent and regulated by cyclin B. Mol. Cell Biol. 15, 932-942.

Furukawa, Y., Iwase, S., Terui, Y., Kikuchi, J., Sakai, T., Nakamura, M., Kitagawa, S. and Kitagawa, M. (1996) Transcriptional activation of the Cdc2 gene is associated with Fas-induced apoptosis of human hematopoietic cells. J. Biol. Chem. 271, 28469-28477.

Hendry, J. H., Potten, C. S. and Merritt, A. (1995). Apoptosis induced by high- and low-LET radiations. Radiat. Environ. Biophys. 34, 59-62.

Hickman, J. A. (1992). Apoptosis induced by anticancer drugs. Cancer Metastasis. Rev. 11, 121-139.

Jacobson, M. D., Weil, M. and Raff, M. C. (1997). Programmed cell death in animal development. Cell 88, 347-354.

Kaufmann, S. H. (1989). Induction of endonucleolytic DNA cleavage in human acute myelogenous leukemia cells by etoposide, camptothecin, and other cytotoxic anticancer drugs: a cautionary note. Cancer Res. 49, 5870-5878.

Kim, Y. S., Jin, S. H., Lee, Y. H., Kim, S. I. and Park, J. D. (1999). Ginsenoside Rh2 induces apoptosis independently of Bcl-2, Bcl-xL, or Bax in C6Bu-1 cells. Arch. Pharm. Res. 22, 448-453

Kishore, N., Sommers, C., Mathialagan, S., Guzova, J., Yao, M., Hauser, S., Huynh, K., Bonar, S., Mielke, C., Albee, L., Weier, R., Graneto, M., Hanau, C., Perry, T. and Tripp, C. S. (2003). A selective IKK-2 inhibitor blocks NF-kappa B-dependent gene expression in interleukin-1 beta-stimulated synovial fibroblasts. J. Biol. Chem. 278, 32861-32871.

Larrick, J. W. and Wright, S. C. (1990). Cytotoxic mechanism of tumor necrosis factor-alpha. FASEB J. 4, 3215-3223.

Lee, M. G., Lee, K. T., Chi, S. G. and Park, J. H. (2001). Costunolide induces apoptosis by ROS-mediated mitochondrial permeability transition and cytochrome $\mathrm{C}$ release. Biol. Pharm. Bull. 24, 303-306.

May, W. S., Tyler, P. G., Ito, T., Armstrong, D. K., Qatsha, K. A. and Davidson, N. E. (1994). Interleukin-3 and bryostatin-1 mediate hyperphosphorylation of BCL2 alpha in association with suppression of apoptosis. J. Biol. Chem. 269, 2686526870.

Meikrantz, W., Gisselbrecht, S., Tam, S. W. and Schlegel, R. (1994). Activation of cyclin A-dependent protein kinases during apoptosis. Proc. Natl. Acad. Sci. U. S. A. 91,
3754-3758.

Mori, H., Kawamori, T., Tanaka, T., Ohnishi, M. and Yamahara, J. (1994). Chemopreventive effect of costunolide, a constituent of oriental medicine, on azoxymethane-induced intestinal carcinogenesis in rats. Cancer Lett. 83, 171-175.

Norbury, C. and Nurse, P. (1992). Animal cell cycles and their control. Annu. Rev. Biochem. 61, 441-470.

Qin, X. Q., Livingston, D. M., Kaelin, W. G. Jr. and Adams, P. D. (1994). Deregulated transcription factor E2F-1 expression leads to S-phase entry and p53-mediated apoptosis. Proc. Natl. Acad. Sci. U. S. A. 91, 10918-10922.

Taniguchi, M., Kataoka, T., Suzuki, H., Uramoto, M., Ando, M., Arao, K., Magae, J., Nishimura, T., Otake, N. and Nagai, K. (1995). Costunolide and dehydrocostus lactone as inhibitors of killing function of cytotoxic $T$ lymphocytes. Biosci. Biotechnol. Biochem. 59, 2064-2067.

Terui, Y., Furukawa, Y., Kikuchi, J. and Saito, M. (1995). Apoptosis during HL-60 cell differentiation is closely related to a G0/G1 cell cycle arrest. J. Cell. Physiol. 164, 74-84.

Tode, T., Kikuchi, Y., Hirata, J., Kita, T., Nakata, H. and Nagata I. (1999). Effect of Korean red ginseng on psychological functions in patients with severe climacteric syndromes. Int J. Gynaecol. Obstet. 67, 169-174.

Tsuruta, F., Sunayama, J., Mori, Y., Hattori, S., Shimizu, S., Tsujimoto, Y., Yoshioka, K., Masuyama, N. and Gotoh, Y. (2004). JNK promotes Bax translocation to mitochondria through phosphorylation of $14-3-3$ proteins. EMBO J. 23 1889-1899.

Villaret, D., Glisson, B., Kenady, D., Hanna, E., Carey, M. Gleich, L., Yoo, G. H., Futran, N., Hung, M. C., Anklesaria, P. and Heald, A. E. (2002). A multicenter phase II study of $\operatorname{tgDCC}-\mathrm{E} 1 \mathrm{~A}$ for the intratumoral treatment of patients with recurrent head and neck squamous cell carcinoma. Head Neck. 24, 661-669.

Wang, X., Deavers, M., Patenia, R., Bassett, R. L. Jr., Mueller P., Ma, Q., Wang, E. and Freedman, R. S. (2006). Monocyte/ macrophage and T-cell infiltrates in peritoneum of patients with ovarian cancer or benign pelvic disease. J. Transl. Med. 4,30 .

Wright, S. C., Zhong, J. and Larrick, J. W. (1994). Inhibition of apoptosis as a mechanism of tumor promotion. FASEB J. 8, 654-660.

Yu, D., Jing, T., Liu, B., Yao, J., Tan, M., McDonnell, T. J. and Hung, M. C. (1998). Overexpression of ErbB2 blocks Taxol-induced apoptosis by upregulation of p21Cip1, which inhibits p34Cdc2 kinase. Mol. Cell. 2, 581-591. 